\title{
Availability of Anti-Corruption Mechanisms to Fight Corruption in Selected Public Institutions in Lusaka, Zambia
}

\author{
Dorothy Mzumara*, Dr. Daniel Ndhlovu \\ University of Zambia, School of Education, Lusaka, Zambia \\ DOI: https://dx.doi.org/10.47772/IJRISS.2021.5336
}

\begin{abstract}
The study examined availability of anti-corruption mechanisms to fight corruption in selected public institutions in Lusaka, Zambia. The study was guided by one objective which was to assessadequacy of the available anti-corruption mechanisms to fight corruption in selected public institutions in Lusaka, Zambia. The research design that was used for the study was hermeneutic phenomenological research design. The sample size consisted of 14 participants while interview guide was used to collect data which was analysed thematically. The findings of the study showed that the available mechanisms were inadequate to fight corruption due to inconsistency in domestication of provisions of the Anti-Corruption Conventions and Protocols and delay in enacting Access to Information Bill. The findings further showed that lack of a Planning Section in the anticorruption commission's structure to identify donor institutions for additional funding and lack of minimum mandatory sentence for corruption offences in the Anti-Corruption Act No.3 of 2012 make the anticorruption mechanisms Zambia has put in place inadequate to fight corruption in selected public institutions. The study recommends among others that progressive and consistency in domestication of the provisions of the United Nations Convention against Corruption, African Union Protocol on Preventing and Combatting Corruption and Southern Africa Development Community protocols into the Constitution of Zambia and Parliament to expedite enacting the Access to Information Bill.
\end{abstract}

Key Words: corruption, bribery, abuse of authority of office, publicadministration and Good Governance.

\section{INTRODUCTION}

\begin{abstract}
A s far as 2013, the fight against corruption existed in Azambia (Mzumara and Ndhlovu, 2021). The fight against corruption has continued to be a top priority at national, regional and international levels as evidenced from common agenda under the SADC Protocol against Corruption, the African Union Protocol on Preventing and Combating Corruption, the United Nations Convention against Corruption as well as other conventions on the subject. At the National level, Zambia has put in place the National Anti-Corruption Policy to fight corruption. However, incidences of corruption still occur.
\end{abstract}

Zambia recognizes the significance of fighting corruption in a holistic and integrated manner to improve public service delivery aimed at achieving good governance and public administrative advancement towards sustainable development of the country. Similarly, Sapkota and Mushimba (2018) observe that corruption remains a major problem in Zambia despite mechanisms such as existence of several anticorruption watchdogs and rigorous changes in the law to curb the vice.

Despite these anti-corruption mechanisms, the Global Competitive Report for 2016 by the World Economic Reform ranked Zambia $118^{\text {th }}$ position with a score of 3.6 out of 138 Countries in terms of set of institutions, policies and factors that determine the level of productivity of an economy. Additionally, Lifuka (2019) asserts that Zambia's performance on the Millennium Challenge Corporative Scorecard for the "Control of corruption" has been dropping. In 2016 the scorecard for Zambia was $87 \%$, this dropped to $85 \%$ in 2017 which dropped further to $84 \%$ in 2018 and $82 \%$ in 2019 .

A review of the Mo Ibrahim Index of African Governance for the period 2014-2017 for Zambia in the areas of Safety and Rule of Law, Transparency and Accountability left much to be desired. The indicator for Zambia was the most declined at -25.0 out of 22 African Countries scoring the last position. The Mo Ibrahim Foundation Africa Governance Report 2019 also shows the performance of the African Continent towards achieving the goals of the Africa's Agenda 2063 and Millennium Development Goals 2030. It therefore becomes imperative to understand adequacy of the available anticorruption mechanisms from the experts with the view of proposing the way forward.

Further, evidence making adequacy of the available mechanisms to be questioned are the Global Economic Crime and Fraud Survey Report of 2018, which recorded that corruption in form of bribery was the most disruptive economic crime experienced in the public sector in Zambia, the Zambia Bribe Payers Index (ZBPI) Report for 2019 which showed that out of 22 public institutions surveyed on bribery as a form of corruption, 18 institutions solicited for bribes from members of the public namely Zambia Police Service Traffic Section, Road Traffic and Safety Agency (RATSA), Local Authorities (Councils), Ministries of Higher and General Education, Zambia Electricity Supply Company (ZESCO), Health Services, National Registration Office, Judiciary (Courts), Zambia Revenue Office (Customs), 
Ministry of Lands, Passport Office, Ministry of Agriculture and Livestock, Road Development Agency, Zambia Police Service (Excluding Traffic Section), Immigration Department, Patent and Companies Registration Agency, Zambia Revenue Office (Tax) and Ministry of Works and Supply. The concern is that these public institutions on behalf of government are the major service providers to members of the pubic in the country. Out of twenty-two (22) institutions surveyed only four (4) institutions never solicited for bribes from members of the public, a situation that is worrying because it shows that the levels of corruption are high indeed amidst the mechanisms that Zambia has put in place to curb and prevent it. Such a situation necessitated an inquiry of this nature to understand adequacy of the available anti-corruption mechanisms at national, regional and international levels from the experiences of experts on corruption.

The President of the Republic of Zambia His Excellence Dr. Edgar Chagwa Lungu in 2016 guided the nation of Zambia on the fight against corruption. His guidance was that "the fight against corruption, in all its forms, is a key tenet of democracy and good governance. In this connection, all patriotic Zambians have a duty to report any case of corruption wherever it manifests itself". Despite the stand and guidance by the President to fight corruption and the existing international, regional and national anti-corruption mechanisms the vice still exists as indicated in the 2018 Global Economic Crime and Fraud Survey and 2019 Zambia Bribe Payers Index Reports. What was not known was how adequate the available anti-corruption mechanisms at International, Regional and National levels were in selected public institutions.

\section{Research Objective}

The objective of the study was to assess the adequacy of the available anti-corruption mechanisms to fight corruption in selected public institutions in Lusaka, Zambia.

\section{RESEARCH METHODOLOGY}

The research design that the study adopted was hermeneutic phenomenology. Hirsch (2015) explains that in hermeneutic phenomenology, a researcher is concerned with the participants' descriptions of the phenomenon as well as the interpretation or meanings of their experiences. This study attempted to make interpretations from the description of different experiences the participants had about adequacy of corruption mechanisms with different realities.

The study population comprised all the Heads of the institutions that were considered to be in the multi-sector approach for fighting and prevention of corruption in Zambia. These were senior officers who had experiences about corruption mechanisms thereby making them experts on corruption prevention.

Guided by several studies on sample size in qualitative studies, the study sample comprised fourteen (14) participants. Mason (2010) states that generally the sample size in qualitative research should neither be too small that it is difficult to achieve saturation nor too big that it is difficult to make deep case-oriented analysis. Similarly, Creswell (2003) recommends between 5-25 respondents as sample size in qualitative research. The choice of the sample size was further supported by Schreiber and Asner (2011) who state that the size of the sample is not an important issue and overbearingly focused on as in quantitative research because the depth and quality of data obtained, its richness in unearthing clearer views of a particular situation and process is considered more prominent than the numbers.

As regard to sampling procedure, a non-probability expert purposive sampling procedure was used for the study. Creswell (2008) states that interpretivist use expert purposive sampling to select individuals that can provide expert information or experiences. Expert purposive sampling according to Frey (2018) involves identifying key informants who can inform an inquiry through their expert knowledge and experiences. As such, participants who had experiences in fighting corruption were chosen to provide expert knowledge on adequacy of corruption mechanisms.

A semi structured interview guide was used to collect data from the study sample. The choice of a semi structured interview guide was based on the fact that it allowed for new questions to be brought up during interviews as a result of what the respondents said.

Data collected was analysed using thematic analysis. The six steps in thematic analysis suggested by Braun \& Clarke (2008) guide the thematic analysis. The first step being familiarisation with the data which involved transcription, rereading of the data and noting down initial codes. In step two the generated initial codes were systematically assigned to interesting features of the data set. The third step was to search for themes. This was done by gathering all data relevant to each potential theme. Step four of data analysis involved reviewing the themes. This was done by checking if the themes related with the coded data extracts and the entire data set. This was followed by the fifth step which involved defining and naming themes. This was done by an ongoing data analysis to refine each theme. The sixth step was report writing. This stage provided a final opportunity for data analysis by selecting appropriate extracts, relating them to the research question and reviewed literature.

The researchers went further to ensure that the data of this study is trustworthy. The four strategies to establish trustworthiness (credibility, transferability, dependability, and confirmability) proposed by Lincoln and Guba (1985) were utilized. Consistent with Lincoln and Guba (1985), this study argues that the strategies are intertwined and interdependent and serve as alternatives to the conventional, quantitative measures for quality such as internal validity, external validity, reliability, and objectivity. Credibility is the replacement for internal validity and is rooted in the truth value, which asks whether the researcher has developed and 
articulated a certain level of confidence in the findings based on the phenomenon under investigation. The truth value derives from an in-depth exploration of the human experience as it is performed by the participants (Krefting, 1990). In other words, truth derives from the participant's lived experiences, which does not necessarily lead to universal truths, but rather an in-depth understanding of that person's unique reality. Transferability replaces the concept of external validity and generalizability, and thus, is concerned with the extent to which the findings from the study could apply to other contexts and settings. Dependability substitutes reliability and asserts that findings are distinctive to a specific time and place, and the consistency of explanations are present across the data. Credibility cannot exist without the presence of dependability, and credibility is truly the root of quality (Lincoln \& Guba, 1985). Last, confirmability gets to the objectivity of the phenomenon under investigation and addresses whether the interpretations and findings are from the participants lived experiences and do not include the researcher's biases. Indeed, the findings of this study are from the expert participants and therefore adds to new knowledge on this topic of corruption mechanisms.

In practice, to ensure credibility, an audit trail throughout the data analysis process exits. In addition, the data collection was done by the doctoral student researcher/lead author of this article. To ensure transferability, we used verbatim transcripts and thick descriptions in data analysis. To ensure dependability, coherent themes were reported across transcripts. To ensure confirmability, we completed several peer and participants' debriefing sessions. To ensure integrity, we remained committed to confidentiality and anonymity with the secondary data set.Ethical considerations were also made to allow respondents have free will to take part in the study and keep their names anonymous.

\section{FINDINGS AND DISCUSSIONS}

The question that the study sought to answer was: what were the participants' experiences in terms of adequacy of the available anti-corruption mechanisms at International, Regional and National levels in selected public institutions to curb and prevent corruption? As such expert knowledge was sought from the participants in the following public institutions: Anti-Corruption Commission, Drug Enforcement Commission, African Parliamentarians Network against Corruption- Zambia Chapter, Transparency InternationalZambia, Ministry of Justice, National Prosecutions Authority, Human Rights Commission, Zambia Police Service, Zambia Institute of Purchasing and Supply, Media Institute of Southern Africa-Zambia, the Cabinet Office, Financial Intelligence Centre, Zambia Public Procurement Authority and The Auditor General's Office. Results revealed that the anticorruption mechanisms at International, Regional and National levels were inadequate to curb and prevent corruption in selected public institutions of Zambia because of the following factors:
Inconsistency in domestication of provisions of the AntiCorruption Conventions and Protocols: The research discovered that inconsistency in domestication of provision of the International Anti-Corruption Conventions and Regional Protocols against Corruption make the anticorruption mechanisms inadequate. A respondent had this to say:

\section{"The anticorruption mechanisms can only be adequate or Zambia can maximally benefit from UNCAC, SADC and AU Protocolsby ensuring that we consistently domesticate all provisions of those conventions into our laws and policies. There are serious gaps in the way we domesticate these protocols which end up to negatively affect the national efforts to address corruption".}

This entails that not all provisions of United Nations and African Union Conventions Against Corruption and Southern Africa Development Community Protocol against Corruption have been domesticated making the anticorruption mechanisms at International and Regional levels inadequate..

Similarly, Gebeye (2015) indicates that failure by Ethiopia to incorporate internationally strategies for instance, provisions of UNCAC and AU Protocol on Combating and Preventing Corruption made the Country's anti-corruption mechanisms in adequate.

The study feels that inconsistency by Zambiain domesticating provisions of the UnitedNations Convention against Corruption, African Union Protocol on Combating and Preventing Corruptionand Southern Africa Development Community Protocol against Corruption and any other similar protocol or convention makes the anticorruption mechanisms inadequate to curb and prevent corruption in Zambia's public institutions. As the result of this inconsistency, the levels of corruption in selected public institutions remain high. It is therefore, the view of the researchers that Agencies that fight corruption such as the Anti-corruption Commission, Financial Intelligence Centre, Drug Enforcement Commission and Public Protectors Office should be tabulating what government has domesticated and what are the gaps in terms of domestication and what the impacts are of not having domesticated the parts of provisions of the Anti-corruption Conventions and Protocols so as to collaborate with the Zambia Law Development Commission to ensure that such provisions are consistently and progressively incorporated in the Constitution of Zambia. Once the user agencies identify the gaps and how those gaps are affecting their effectiveness and the national efforts to address corruption then the anticorruption mechanisms would be adequate to curb and reduce corruption in public institutions.

\section{Delay in Enacting Access to Information Bill}

Participants unanimously responded that without the enactment of the Access to Information Bill, anticorruption mechanisms may not be adequate. For instance, one of the participants said that: 
"Parliament with the help of all stakeholders should ensure that the Access to information bill is enacted as soon as possible to give citizens freedom to access any information e.g. related to the public service and corrupt practices which will contribute to the adequacy of the anticorruption mechanisms."

Generally, research in Africa shows that access to information is a tool that partly contributes to adequacy of anti-corruption mechanisms to curb and prevent corruption at the International and Regional levels. For instance, the study done by Shado (2004) in Uganda shows that legislating on access to information is a tool that African States should strongly consider using if they are committed to exposing and combatting corruption, however, having the law on access to information is not enough without political will to encourage transparency and public participation in governance especially at senior level.

It is the view of the researchers that access to information promotes good governance principles of transparency, accountability and integrity in the systems, processes, procedures and structures of public administration which reduces opportunities for corruption. Once the Access to Information Bill is passed by Parliament the public will have the right to access information e.g. on who is alleged to be corrupt as and when they need it in turn acting as a corruption deterrent. Inadequate law on freedom to access information is a setback that may have contributed to high levels of corruption in the Country. Freedom to accessing information as a corruption combating tool at the national level facilitates knowledge and discussions on such issues as corruption in form of bribery and abuse of authority of office, misappropriation and mismanagement of public resources which negatively impact on the process of development of the country.

Delay in enacting Access to Information Bill is a breeding ground for corruption practices which makes the anticorruption mechanisms at the national level inadequate. Therefore, enactment of the Access to Information Bill would partly contribute to adequacy of anticorruption mechanisms at the national level to help reduce corruption in public institutions.

\section{Lack of a Planning Section in the Anti-Corruption} Commission's Structure

Lack of a Planning Section or Unit in the Structure of the Anti-Corruption Commission to engage donor institutions for additional funding other than depending on inadequate funding from Government has been revealed by respondents as a factor that makes the anti-corruption mechanisms inadequate to fight corruption at a National level. A respondent stated that:

"my institution has a Planning and Research department where we also have a liaison person. Once we identify donor institutions that can help us with funding, the liaison persons constantly engage those donors or corporate partners to ensure that we remain compliant to the bilateral agreements, for instance, if there is a new approach to the way they will provide finances, then we are also able to adjust through the Planning Unit. Institutions like ACC they need that kind of structural arrangement so that they can move away from totally depending on government for financing that is the only way they are going to solve the problem of inadequate funding which makes the anticorruption mechanisms inadequate.".

This paper takes note that absence of a Planning Unit or Section in the ACC structure contributes to inadequate funds to meet the objectives of the anticorruption mandate. There is need for the Commission to adjust its operational structure to include the aspect of planning that will take care of sourcing for external funding to benefit from bilateral and multilateral assistance like some of the public institutions that participated in the study.. Another respondent pointed out that:

"Another aspect is training of staff who can step-up to the challenge of cybercrime which usually involves corruption. Most of such training is expensive and developing countries like Zambia cannot afford to have all its staff especially from the Anti-corruption Commission trained and acquire advanced technological skills".

In analyzing these responses, lessons can be learnt from Europe and Australia, as evidenced by the research conducted by Anttiroiko (2017) in Finland on emulating models of good governance: Learning from the World's Least Corrupt Countries which discovered that anti-corruption mechanisms for Finland and New Zealand were adequate at a national level because the two countries had put up low profile anticorruption measures that provided a fast track to good governance aiding the fight against corruption.

The researchers observe that Finland and New Zealand are Developed Countries that have good governance structures in place and may not source for international funds to implement anti-corruption programs at National level. They have sophisticated technology to even train anti-corruption experts to curb and prevent corruption. Since the two countries are the world's least corrupt countries, Zambia can learn something from them.

\section{Absence of Position of Procurement General in Government}

Lack of Procurement General Position in Government has been pointed out by respondents as one of the reasons for having inadequate anti-corruption mechanisms. One of the respondents had this to say:

"historically, the position of Procurement General was resident in the former Tender Board so the Tender Board was doing some procurement in the Ministry. When the Procurement Act No.8 of 2020 was amended the position of Procurement General was removed. As a result procurement staff functionally does not report to anyone at the most senior level. The Procurement General will ensure that there is value for money and will anchor the procurement process in 
government. Most people erroneously think that that is the role of Zambia Public Procurement Authority but it is a regulator that formulates laws not controlling procurement so the actual implementation of procurement process is very void in government making the corruption mechanisms inadequate."

This finding cements the remarks by His Excellence, the President of Zambia Dr. Edgar Chagwa Lungu who stated that public procurement had become an avenue through which Government had been losing huge sums of funds via cartels, unrealistic pricing of goods and services and other unethical practices that were aimed at manipulating the system for personal gain. As such, he directed the various units of Government charged with the responsibility of investigation and prevention of unethical practices such as corruption and bribery to be on high alert and quell any potential frauds in the public procurement system (www.lusakatimes.com/2015/11/27).

Similar views were expressed by Naidoo (2012) who indicated that many societies had recognized corruption as a major hindrance to good governance in the public sector, for instance, the South African government had prompted the public sector to focus on anticorruption measures as part of their mechanisms to prevent and curb corruption but it was evident that the mechanisms were inadequate due to poor governance practices.

The researchers feel that lack of position of the Procurement General in the Government of Zambia is a poor governance practice which makes the anticorruption mechanisms inadequate at the national level leading to high levels of corruption in the public institutions. The absence of highranking office in charge of procurement in Government may be a loophole for corrupt practices in procurement because the actual implementation of the procurement process at the national level is not overseen or managed by a higher-ranking office to offer policy direction that would promote good governance principles such as integrity and accountability that would counteract corruption. Therefore, lack of policy direction in procurement process makes the anticorruption mechanisms at the national level inadequate.

Absence of Human Rights Principles in the mechanisms used to fight corruption:

Respondents unanimously pointed out that absence of Human Rights Principles in the Anti-Corruption mechanisms make the anti-corruption mechanisms inadequate at the national level. One respondent stated that:

"Corruption is a violation of human rights but you would find that strategies used to fight corruption at all levels do not include human rights in terms of principles even though the Constitution has Bills on human Rights. Fighting corruption can only be won if such principles are integrated into the mechanisms used against corruption. Corruption and human rights violations are married together. for instance, where there is corruption there are human rights violations."

The revelation of this research corroborates with those of by Ajibade (2008) that showed that in Nigeria, corruption is a complex problem and solving it requires multiple of strategies for instance mainstreaming human rights into Anti-Corruption mechanisms.

The researchers were of the view that corruption for instance, in form of bribery and abuse of authority of office cannot be addressed without addressing human rights violations because the two are intertwined. So, failure to address the two together poses a serious challenge to combat and prevent corruption in Zambia probably that is why the levels of corruption in the country are high despite existing national anticorruption mechanisms. Thus, the need to mainstream human rights principles in the anticorruption mechanisms to cover the gap of inadequacy in the anti-corruption mechanisms at the national level.

Once Human Rights principles are mainstreamed into the country's anticorruption mechanisms, they may provide scope for important tools such as accountability, transparency and participation necessary for a successful and sustainable anticorruption campaign. Accountability, participation and transparency are some of the good governance principles that need to be observed in public administration of services and goods in the government of Zambia. Anttiroiko (2017) asserts that good governance aids the fight against corruption. Therefore, it is the opinion of the researchers that mainstreaming human rights principles in the anticorruption mechanisms is fundamental towards adequacy of the mechanisms the Country is using to curb and prevent corruption at the national level because human rights principles promote good governance which is a pillar against corruption.

Servingministers are not captured as public officials under the Anti-corruption Act No. 3 of 2012.

The findings have also revealed that the Anti-corruption Act No. 3 of 2012does not capture serving ministers as public officials making the anti-corruption mechanisms at the national level inadequate. One of the respondents opined that:

"the Anti-corruption Act should include ministers as public officials so that they can also be accountable through the anticorruption mechanisms. Since ministers hold legislative offices as they are elected or appointed to exercise public functions for and on behalf of members of the public who are their electorates, they need to be checked by the Anticorruption Act once found wanting. Such a provision in the law would encourage Ministers to be committed to the fight against corruption."

Ministers hold positions of trust involving a duty to act in the public interest. Therefore, their ultimate loyalty must be to the public interest. In addition, another respondent said: 
"It is a serious anomaly in the fight against corruption for Ministers not to be recognized by the law as public officials especially that they run or control Ministries composed of public officials/officers who some of them engage in corrupt practices as such the anti-corruption mechanisms can never be adequate, how do you expect Ministers to be committed?"

Consistent with these views are those of Igiebor (2019) that pointed out that genuine commitment by leaders from the top to down is needed to fighting corruption in Nigeria. The finding corroborates research findings generally in Africa and Asia. For example, findings by Assiamah, Asamoah and OseiKojo (2014) on Africa revealed that bureaucratic and political elites who are parliamentarians should take the lead in fighting corruption by conducting themselves in a manner that would inspire trust and confidence in the entire political system. Additionally, the study by Tummala (2009) in India which dealt with the ambiguous problem of corruption among public officials both elected and appointed discovered that among the plethora of reasons for failure to combat corruption was the inadequate and inefficient enforcement of anticorruption mechanisms. Further, the study by Naidoo (2012) in South Africa found out that the anticorruption measures were inadequate because of weaknesses and gaps in legislation.

\subsection{Absence of provision for minimum mandatory sentence in the Anti-corruption Act No.3 of 2012.}

The study found out that one of the factors that make the anticorruption mechanisms at the national level inadequate is the absence of provision for minimum mandatory sentence on corruption offences in the Anti-Corruption Act No.3 of 2012. For instance, a respondent said that:

"there is need to amend the Anti-Corruption Act No. 3 of 2012 to provide for minimum mandatory sentence to deter would be offenders, you would find that someone is corrupt but the court gives him a suspended sentence because the courts are not guided by the law and generally, courts are lenient to punish people that are corrupt as a result, would be offenders may get encouraged".

Similarly, Iddrisu (2019) whose study was in Ghana revealed that government agents who are caught in the act of corruption are only made to refund the amount involved without repercussions to them. In situations where they are penalized, the punishment is far less than the rewards for deviation to good. This makes acts of corruption more lucrative in African Countries. Additionally, Igiebor (2019) in Nigeria states that offenders of corruption needed to be severely punished.

The researchers note that currently there is a problem in sentencing regime on corruption offences where courts can impose unreasonable low sentences which are not adequate to deter would be offenders therefore promote corrupt practices. It is the view of the researchers that lack of provision for minimum mandatory sentence in the Anti-Corruption Act weakens the law to fight corruption adequately in the public institutions at the national level, probably that is the reason why high levels of corruption are exposed in public institutions. Once the Anti-Corruption Act No. 3 of 2012 is amended to include minimum sentence on corruption offences, the anticorruption mechanisms may be adequate to fight corruption. Thus, even would-be offenders would be prevented against corruption.

\section{CONCLUSIONS}

Based on the above discussion, it was safely concluded that the international, regional and national anticorruption mechanisms were inadequate to fight corruption in public institutions in Zambia. Additionally, the findings offer a guide to make the anticorruption mechanisms adequate to fight corruption in public institutions.

\section{RECOMMENDATIONS}

Based on the findings, it was recommended that among others, progressive and consistency in domestication of the provisions of the United Nations Convention against Corruption, African Union Protocol on Preventing and Combatting Corruption and Southern African Development Community protocols into the Constitution of Zambia and Parliament to expedite enacting the access to information billto make the anti-corruption mechanisms at International, Regional and National levels adequate to curb and prevent corruption such as bribery and abuse of authority of office in selected public institutions thus promote good governance in public administration of goods and services offered to members of the public.

\section{REFERENCES}

[1] Adebayo, A. A. (2013). Youth's Unemployment and Crime in Nigeria: The Nexus of Corruption and Poverty in the Quest for Sustainable Development in Nigeria. International Journal of Sociology and Anthropology, 5(8), 350-357.

[2] Anttiroiko, A. (2017). Emulating models of good governance: Learning from the developments of the world's least corrupt countries. International Journal of Public Policy, 13 (12), 21-35.

[2] (bbc.com/news/world-Africa)

[3] (BBC Focus on Africa)

[4] Braun, V., \&Clarke, V. (2008). Using thematic analysis in psychology. Qualitative Research in Psychology. 3 (2), 77-101.

[5] Budget Performance Report for Zambia 2018

[6] Carpenter, C. (2013). Phenomenology and rehabilitation research. Research Methods in Health Foundation for Evidence Based Practice ( $2^{\text {nd }}$ Ed. Ipp 115-131) South Melbourne, Australia, Oxford University Press.

[7] Efthymiou, E. D. (2010). International law and normative partisanship: The case of corruption in Tanzania, Journal of Politics. 1-32.

[8] Financial Global Integrity Report 2016

[9] Frey, B. (2018). The SAGE Encyclopedia of educational research, Measurement, Evaluation.

[10] Gebeye, B.A (2015). The legal regime of corruption in Ethiopia: An Assessment from International Law Perspective. Oromia Law Journal, 4 (1), 73-124.

[11] Global Competitive Report 2016

[12] Global Economic Crime and Fraud Survey of 2018

[13] Hirsch, E.K. (2015). Phenomenology and education research. International Journal of Advanced Research, 3(8), 251-260. 
[14] https://www.unicef.org

[15] https://www.tradingeconomics.com>Zambia

[16] https://www.lusakatimes.com>Headlines (/2015/11/27)

[17] Human Development Index Report (2018)

[18] Krefting, L (1990). Rigor in qualitative research: The assessment of trustworthiness. American Journal of Occupational Therapy, Vol43, No.3, Pg 214.

[19] Kunda, G. (2013). Speech delivered at the SADC convention held in Lusaka.

[20] Lifuka, R. (2019) Transparency International Zambia Chapter President's speech at launch of the 2019 CPI, in Lusaka Zambia.

[21] Lincoln, Y. S., \& Guba, E. A. (1985). Naturalist inquiry. Beverly Hills, CA: Sage.

[22] Living Conditions Monitoring Survey Report for Zambia 2018.

[23] Lungu, E.C (2016). Speech of the official opening of the $1^{\text {st }}$ session of the $12^{\text {th }}$ National Assembly of Zambia.(LusakaTimes.com).

[24] Mason, M. (2010). Sample size and saturation in qualitative research.

[25] Mbaku, J. M. (2016). International law and the fight against bureaucratic corruption in Africa, Arizona Journal of International and Comparative Law,33(3), 662-764.

[26] Ministry of National Development and Planning Report 2018.

[27] Mo Ibrahim Foundation African Governance Report on Agenda 2063 and 2030: Is Africa On Track? 2019 Report.

[28] Mzumara, D., \& Ndhlovu, D. (2021). How a good governance model can be developed to enhance management of integrity committees (ICs) to prevent corruption in the public institutions of Zambia, Lusaka, International Journal of Humanities Social Sciences and Education (IJHSSE), 8(2), 110-122.

[29] Naidoo, G. (2012).Ethical leadership principles in South African public administration lost opportunity or alive with possibility. Mediterranean Journal of Social Sciences, 3 (12), 1-21.

[30] Ndeleki, C. (2005). Dissertation on corruption and national plunder in Zambia: Is there adequate law, University of Zambia.
[31] Ogwang, L.V.O (2007). Dissertation on rethinking Kenya's anticorruption strategies: Lesson from Botswana. School of Law, University of Pretoria, South Africa.

[32] Ojo, E.O. (2016). Combating systematic corruption in Africa: altitudinal, attitudinal, confrontational or constitutional? Journal of Siberian Federal University, Humanities \& Social Sciences. 9(9), 2092-2123.

[33] Salihu, H.A., \& Jafari, A. (2020). Corruption and anticorruption strategies in Iran: An overview of the preventive, detective and punitive measures. Journal of Money Laundering Control, 23(1), 77-89.

[34] Sapkota, J. B \& Mushimba,M. (2018). Understanding Corruption in Zambia: An analysis of the Challenges in Eradicating the Scourge, January 2018.

[35] Sata, M.C. (2012). Speech by the former President of Zambia at the commemoration of the international anticorruption day on $9^{\text {th }}$ December

[36] Schreiber, J.B \&Asner, K. (2011). Educational Research. Wiley

[37] Seventh National Development Plan Annual Progress Report for Zambia 2018.

[38] Transparency International Perception Index Report 2017.

[39] Trading Economics.Com/Zambia/Unemployment-rate.

[40] Tummala, K.L. (2009). Combatting corruption: Lessons out of India. The Yale Law Journal, 10 (1), 34-58.

[41] Ucha, C. (2010). Poverty in Nigeria some dimensions and contributing factors. Global Majority E-Journal, 1(1), 46-56.

[42] UNDP Human Development Index Report 2018.

[43] Usher, A.D. (2010), World Report, Vol 376.

[44] World Bank Report on Economy (2019).

[45] World Health Report (2007).

[46] Zambia Annual Progress Report on Seventh National Development Plan 2018.

[47] Zambia Bribe Payers Index Survey Report 2017

[48] Zambia Bribe Payers Index Survey Report 2019

[49] Zambia Budget Performance Report 2018.

[50] Zambia National Anti-Corruption Policy Document 2009. 